\title{
A core for flexibility ${ }^{1}$
}

\author{
Mary L. Chute \\ New Jersey State Library \\ E-mail: Mchute@njstatelib.org
}

\begin{abstract}
This paper addresses issues of inventing the future of information services from the perspective of a practitioner.
While recognizing deep dedication to privacy, openness, commitment to the under-served, and long-term stewardship of the cultural record, the author acknowledges the impossibility of designing a precise curriculum for mid-21st century information professionals and proposes core subject areas providing an adaptable 21 st century skill platform.

Enduring goals of information services professions evolve due to commitment and responsiveness to changing communities and needs, and adaptation to new technologies. The "library" or "archive" is no longer a warehouse for content, but rather a set of services designed by information professionals who simultaneously are reinventing themselves. Our institutions continue as environments that support development of the learner, promote information discovery, and serve as community anchor institutions.

The information professional must be equipped with attitude and analytic capabilities designed for problem solving, able to
\end{abstract} work both independently and in teams, and capable of constant adaptation. Proposed core curriculum areas:

- strategic thinking and facility with evidence-based planning and evaluation,

- ability and skills necessary for trends analysis,

- ability to effectively teach, train, and empower myriad learner types,

- ability and skills to respond to the needs of each unique customer.

Keywords: Information professionals, Librarianship, Library and Information Science, 21st century skills, 21st century learners, core curriculum

The proposition: Imagine what kind of future you want to see and how to prepare information students to invent that future.

I address this thought problem not from the perspective and perceptions of a library science educator, a scholar, or an academician, but rather from the perspective of a practitioner: a state librarian, a public library director, and a government official. Over the course of my career my work product has been less focused on specific preparation and credentials of our library workforce and more concerned with designing, developing, and delivering services that make a difference. My strategy has been one of planning for desired outcomes. With this type of approach one envisions the desired state of affairs, assesses reality, determines the gap between the ideal and the real, and more or less reverse engineers a service intended to provide resources that lead to change.

In the model of past experiences, the questions considered would include: What do we determine are the current and will be the future needs of our communities of users, today and tomorrow? What services and products might we produce to address those needs? On delivery of services developed in response to those real and anticipated needs, what difference could be made? What other players, competitors, or partners may have a role in this space? What might be the impact on unique individuals, groups, or families, and on the community as a whole? In my prior experience, the answers to these questions

\footnotetext{
${ }^{1}$ This work is licensed under the Creative Commons Attribution-Noncommercial No Derivations Works 3.0 Unported license. You are free to Share this work (copy, Distribute and transmit) under the following conditions: attribution, noncommercial and no derivative works. To view a copy of this license, visit http://creativecommons.org/licenses/by-nc-sa/3.0/.
} 
have provided a "backwards" path to determine the desirable outlook, approach, and skill sets for the most effective staff assignments. I propose that similarly this approach will inform our preparation of the information and service oriented professionals for 2050 .

\section{The prediction}

I have always found the concept of predicting the future to be energizing and exciting. At its most frivolous, the activity presents a hybrid image somewhere between a carnival fortune teller and futuristic science fiction. But when it comes to imagining the future of our professions, this is not frivolous fun and games, but rather, serious business. Being tuned into trends and stretching our imaginations to anticipate subsequent developments are about being aware and being prepared. Envisioning the future is grounded not in guesswork regarding what might occur, but hinges on our awareness of the present - and the past. Those who succeed at this thought problem exercise may well contribute to the vibrancy and viability of the information service professions about which we are all concerned.

Information Professionals 2050 - Over the past 15 years, "long range planning" has shifted from referencing a 10-year plan, to a 5-year plan, to a 3-year plan. And when we venture into imagining 3 years out, chances are good that our actual action plan will be targeted at a more conservative 12-18 months. Looking forward 38 years, anticipating the needs of and technologies available to the information seekers of 2050 simply is not feasible. In today's era driven by exponential growth in information and everchanging technologies, can we possibly imagine and strive to design a curriculum for the descendants of today's information professionals? Perhaps not exactly, but I would propose that we can indeed design a core of subject areas that will provide a strong 21st century skill platform for our heirs.

At the Institute of Museum and Library Services (IMLS) we have just completed our strategic plan for 2012-2016. The document is available on the IMLS Web site and is entitled Creating a Nation of Learners. The plan presents a vision of "a democratic society where communities and individuals thrive with broad public access to knowledge, cultural heritage, and lifelong learning", and expresses the mission of IMLS as providing leadership through research, policy development and grant making, and inspiring libraries and museums to advance innovation, lifelong learning, and cultural and civic engagement. This vision and this mission are not new concepts. Although perhaps articulated differently at various stages in our history, I propose that they have been embedded in the purpose since the middle of the last century, since their first iteration of the federal aid programs that have provided support for the nation's libraries, archives, and museums. Likewise, and perhaps more directly to the point, IMLS's new three primary outward facing goals designed to further the vision and mission also can be seen as timeless. These three goals focus on the roles that our institutions play as places that support the development of and engage the learner, promote discovery of knowledge and access to cultural heritage through their stewardship, and serve as community anchor institutions that strengthen community by helping individuals help themselves and others. This last goal in particular is revealed through many diverse functions ranging from high-speed broadband access, to preschool support for early learning, to providing resources and a forum for community discussion and problem solving.

\section{The change}

We all recognize that information professionals dealing with change is not a new concept. For decades we have been inundated with change on every front: changing technologies, changing demographics, changing expectations. When I first arrived at IMLS in 2002 we were just beginning to lay the foun- 
dation for what later became the Laura Bush 21st Century Librarian grant program. We were studying how the professions themselves were changing. The director of IMLS, Dr. Robert S. Martin, who was an archivist and librarian, provided key messaging that we used on multiple occasions over his four year term regarding the "blurring of the boundaries". I would maintain that although this fluid state of professional boundaries exists today, and I anticipate it will continue into the future, the nature of the fluctuation has changed.

In 2002 the boundaries being referenced were the boundaries among libraries and archives, and even museums. By 2010, under our next director, Dr. Anne-Imelda Radice, a museum professional, IMLS hosted a symposium which came to be nicknamed "CHIPs" (Cultural Heritage Information Professionals). At this stage there was an awareness of potential for a base curriculum designed to prepare students for one of several ultimate careers and even allow for mid-career growth and career change without starting over.

Today, in 2012, new alliances are being made and different boundaries are blurring. This blurring is totally understandable in that "information" has become increasingly important. Information is the foundation for most activities in today's world. With limited and diminishing economic resources for critical social services, partnerships are being formed around employment services, early learning, multicultural integration, school readiness, youth development, and an increasing demand for senior services. For today's libraries the permeable boundaries seem to be more in the area of social and educational support services and less strictly in the cultural heritage arena. I would predict that tomorrow the responsive nature of our libraries will continue to evolve. One of our libraries' greatest strengths over the decades has been their commitment to adapting to new technologies, changing needs, and evolving communities. The coming decades will bring the next generation of information professionals a whole new set of issues and fresh partners that will draw them across different boundaries.

\section{The constancy}

In my personal prediction of the future, the precise issues, the exact partners, the particular constituent groups, the pressing information needs may all change, but the mission, the purpose, the heart of the craft of connecting people to each other and ideas will endure. The specific skill sets, the vehicles, the tools will evolve even more rapidly than today, but the purpose and goals of the profession will continue and be played out in different ways.

Over the last decade IMLS has been working with libraries, archives, and museums to promote and hone their role in supporting the 21st century learner. And over the past five of those years we have focused specifically on 21 st century skills. These skills are not, as one might anticipate, tethered to particular burgeoning technologies. They do not include detailed specific subjects such as computer engineering, software development, or even troubleshooting mobile devices. The key areas of development for today's learner that will best position them for success in the 21 st century are broader capabilities and approaches to growth and learning. Keys to success include development areas such as critical thinking, curiosity, creativity, the ability to communicate effectively, teamwork, flexibility, the ability to collaborate, and at the base of it all, global awareness. Although they likely have always been the hallmarks of success throughout the ages, these skills are even more important as we look to a future that presents technologies and possibilities that are evolving so rapidly we can hardly imagine how to prepare for them. Like the learner of the 21 st century, the information professional of the mid-21st century needs to be equipped with attitude, outlook, and analytic capabilities that position him or her for problem solving, and constant adaptation, for independent work and to collaborate effectively in teams. 


\section{The core curriculum}

As the essential areas of subject area familiarity and expertise both broaden and deepen, librarianship is becoming an umbrella profession. There are many ways to be a librarian. I would like to expand on two major, almost conflicting trends. The first leads to familiarity with an increasingly broad range of information in terms of subject and format. Following this trend would prompt us to prepare and equip the information professional of 2050 to be a generalist who is the master of the overview and is adept at making the connections between people and the vast variety of information they need. The second trend focuses on the increasing need for in-depth subject understanding and would prompt us to shape the profession in a way that requires multiple degrees and would encourage the information professional to pair their information navigation skills with a second (or third?) area of intense study so as to provide deep subject matter expertise. For either of these career paths; the information generalist or the information specialist, we are challenged to accurately imagine the exact content. I propose that from this distance our energy needs to be focused not on the evolution of specific content, but on developing the best approach to the information professions.

What are the critical components of a curriculum designed to prepare the information professional of 2050 - or any decade, before or after - to fulfill the primary purpose and goals of their chosen career? I propose the following four areas as a starting point. First and foremost comes strategic thinking and facility with evidence-based planning and evaluation. This is today's terminology for an approach to developing and sustaining an enterprise through planning based on substantiated need and design for problem solving and impact. Closely interwoven with strategic thinking, yet worthy of standing as a separate category, are the ability and skills necessary to engage in trends analysis. The third might be "pedagogy". The ability to effectively teach, train, and empower the learner of tomorrow is essential. We can already anticipate myriad learner types: early learners needing at least basic understanding in multiple languages, adult learners retooling for unanticipated and as yet unimagined careers, and communities consisting of learners with little in common. And lastly, the driving force behind the other three is the skill and ability to respond to the needs of each unique "customer". This customer service responsiveness, with the ability to relate to each of many varying segments of the population, and connect each one or each group with the particular information, resource, or conduit that is needed to meet their needs, is - and always has been - what positions the best information professionals at the top of their field. In a world of expanding options and resources the information professional will need to be even more expert at the "concierge" role of connecting individuals to the precise resource or data that they need.

A notable added value to a core curriculum approach would be the almost universal applicability of what is being taught across this field and others. In our information professionals we are creating the ultimate 21 st century learner. I can only guess, but I would like to think that this type of preparation not only would draw students to the profession, but that the flexible applicability of the skills would add to the duration of their engagement within this cluster of information service careers. There is a recognized tendency for today's student to adopt multiple careers over his or her lifetime. In light of this consideration, we add value by designing a course curriculum that prepares tomorrow's student with the most flexible background possible. In addition, as noted above, the expertise desired in information professionals is becoming ever broader. It includes technologies that range from papyrus to "the cloud". If the information professions are to be seen as one umbrella profession, we need to acknowledge that it provides a spectrum of opportunities, from preservation to digitization to reference to technology training and development; from community anchor to digital steward. Once invested in a core of skills that offer a variety of opportunities, it is not hard to imagine that the information professional of tomorrow 
may well engage in multiple information professions. This being said, it is notable that we need a more robust system of continuing education beyond degrees. The degree is the beginning and the field will need more than the occasional conference to prepare, engage, and reward those who continue to grow and develop.

\section{The craft}

Just as the scope and delivery mechanisms for information are expanding on a yearly, monthly, or even daily basis, so are the possible iterations of "the information professional". The "library" or the "archive" is ceasing to be seen as a warehouse, but rather is evolving into a set of services, services designed for and by information professionals who simultaneously are reinventing themselves. These librarians and archivists are responding to the changing demographics and needs of their users, 21st century learners. These information generalists and specialists recognize the unique nature of every customer and are responding to the need for customization.

With information at the foundation of so many of today's activities, as a field we need to support the growing professional diversity, while still maintaining the professional identity. If we do not, we will likely find that commitment to our shared professional values is at risk. Where other than under this umbrella of information professions do we find such deep dedication to privacy, openness, commitment to the underserved, and long-term stewardship of the cultural record?

In designing their learning opportunities we need to model the same practice. The craft of connecting people to each other and ideas continues to be needed and of great value. Provided with the right preparation and approach, information professionals should be one of our most valuable resources in paving the way to success in the mid-21st century, just as they did in the 19th and the 20th.

\section{Disclaimer}

The views expressed are those of the author and do not necessarily reflect the official position or policies of the Institute of Museum and Library Services. 